\title{
Site Suitability Analysis for Road in Mountainous Terrain Region of Papua New Guinea (A Case Study of Salt Noname Karimui District of Simbu Province)
}

\author{
Poi, N., ${ }^{1}$ Samanta, S. ${ }^{2 *}$ and Sekac, T. $^{3}$ \\ GIS Section, Department of Surveying and Land Studies, The PNG University of Technology, Lae, Morobe, \\ Papua New Guinea, E-mail: nebarepoi@gmail.com, ${ }^{1}$ rsgis.sailesh@gmail.com, ${ }^{2}$ tingneyucsekac@gmail.com ${ }^{3}$
}

\begin{abstract}
Road infrastructure developments in rural Papua New Guinea (PNG) have not picked up pace due to mountainous and difficult geographical landscape. Hence road accessibility in rural Salt Nomane Karimui (SNK) District of Simbu province is emerged as a serious concern particularly with regard to impact of poor accessibility and mobility on agricultural produce and ability to access public amenities. Governing agencies have plans in place for road connectivity in Karimui region and other parts of SNK district but their attempts remain unsuccessful due to difficult geography and lack of technical data. This study utilized Geographical Information System (GIS) and multi-criteria evaluation (MCE) techniques through Analytic Hierarchy Process (AHP) to develop site suitability model to evaluate mountainous terrain and forest road connectivity in SNK district. The approach looking at in this research is to classify suitability factors into two principle classes' i.e. Geophysical and Geotechnical influence as principle factors. Relatively important geophysical factors influencing road suitability sites including altitude, slope, river network, road and rainfall data are integrated to generate alternatively suitability map one. Geotechnical factors influencing road suitability sites including Lithology, Soil Texture and Landform are integrated to generate alternatively suitability map two. The final suitability map is produced by integrating the thematic layers of two principle factors and classified into five suitability classes i.e. less suitable, marginally less suitable, moderately suitable, suitable and highly suitable.
\end{abstract}

\section{Introduction}

In developing countries like Papua New Guinea (PNG), road network plays very important role for any development programs in rural areas. A better road link to rural village provides better access to markets and other public amenities. A research carried out by Adedeji et al., (2014) and Davis (2000) summarised that efficient and effective rural road connectivity provides better access to public amenities and means of transporting agricultural products to nearest market centers, easy exchange and collection of goods and services, dissemination of information and promotion of rural economy. The role of rural roads is very important in PNG where majority of the population resides in rural areas and the main source of their earning is based on agriculture products (Samanta et al., 2011). The poor state of road connectivity combined with undependable transportation services in rural parts of PNG has an adverse impact on access to markets and public amenities. Rural SNK district of Simbu Province is one of the mountainous and complex geographical terrain regions of PNG and road transport is emerged as a serious concern particularly with regard to the impact of poor accessibility and mobility on agricultural produce and ability to access public amenities. The national government has invested a lot of funds on road infrastructure in rural areas, but their objectives are not met due to technical challenges. The most obvious ones are lacking reliable locational data and appropriate planning tool for planning right location.

The primary objective of this research is to develop suitability model to evaluate forest terrain and mountainous road investment with regard to technical requirements using GIS and MCE approach. Road investments in forest terrain and mountainous region a number of criteria may be required to evaluate in choosing the best alternatives. Although a number of methods have being in-used for the development of weights for MEC approach, the Analytic Hierarchy Process (AHP) developed by Satty (1980) is the most popular techniques for decision-making process through pair-wise comparison method. In MCE approach, AHP process is a tool that can be used to solve any complex decision problems by structuring them into a hierarchical framework. A research 
carried out by scholars (Shiba, 1995, Abdi et al., 2009 and Coulter et al., 2006) summarised that use of AHP is to find out the benefit structure of a road network and particularly useful tool for resolving political, economic and environmental conflicts and to provide a consistent and quantifiable approach to problems involving with multi-criteria evaluation techniques (Jun, 2000). Over the period of planning process, this model study will appear as planning tool to aid engineers and decision maker's to incorporate technical challenges and budget requirements for cost effective and environmentally friendly approach for road connectivity in rural SNK district. One researcher (Dean, 1997) has highlighted the importance of finding cost effective and environmentally friendly path for new road as highly desirable. Whilst this study intends to provide integrated geophysical and geotechnical suitability alternatives by utilising GIS applications with MCE approach. The influential suitability themes such as lithology, slope, altitude, rainfall, soil type, drainage, road network and landform were evaluated through data integration techniques by using suitability rating and weighting with simple statistics leading up to multi-criteria decision through APH approach to bring out alternatively suitable sites fora cost-effective and environmentally friendly approach.

\section{Description of the Study Region}

This research was carried out in Salt Nomane Karimui district of Simbu Province in PNG (Figure 1). Rural SNK is geographically the most isolated region in the province depicted by fast flowing rivers and steep mountain ranges situated south of Kundiawa, Simbu Province head quarter.

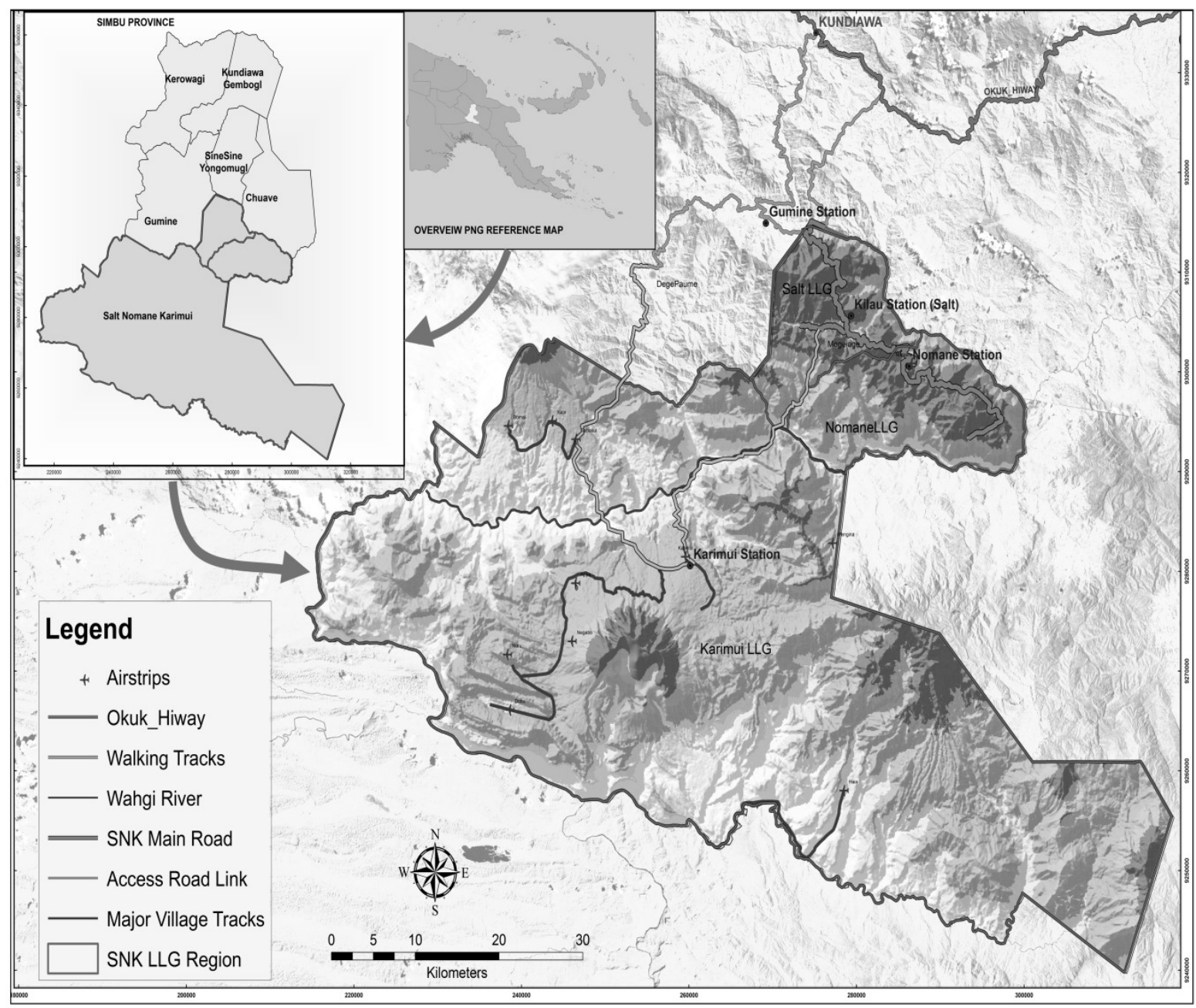

Figure 1: Locality map of the study area 
It comprises of three Local Level Governments (LLGs) namely Salt, Nomane and Karimui. Salt LLG is approximately $25 \mathrm{~km}$ South of Kundiawa, while other two are $35 \mathrm{~km}$ and $55 \mathrm{~km}$ respectively further south of Kundiawa. It covers a land mass of about 35086 ha and have a total population of 52159 excluding children as recorded by the national census of PNG, 2011.

Due to its complicated geographical landscape, Karimui LLG region is disconnected from road network and operating in a complete isolation. Karimui is the biggest LLG region in terms of landmass. It covers about 302 000ha and takes up about 50 percent of the provincial landmass. Nomane and Salt LLG regions are merged by road accessibility and jointly accessing public amenities at the district governing administrative unit. The poor accessibility and mobility on agricultural produce and ability to access public amenities keep the highly potential development areas of Karimui region remain isolated.

Northern and southeast part of Karimui region is composed of mountain ranges and steep terrain ridges while wider extend of central to southern region is obviously flat spreading over southwestern and part of south-east fringes. It has geographically advantageous landscape and volcanic soil that produce some of the top quality economical crops in the province. It is obviously well-known for growing high quality organic coffee, rice and recently cocoa and vanilla are getting underway unlike other parts of the district and province as a whole. Besides, it hosts unharmed virgin forest famously termed as the home of beautiful plants and diverse animal's species in the region. Subsistence farming is their only traditional practise of survival where people mostly farm land for food and shelter. Due to its natural fertility and geographically favourable landscape gives good yield for large scale economical crops. As a result, the potential of economic activities in this region remain relatively high compared to other parts of the district and Simbu province as a whole.

\section{Methodology}

\subsection{Software and Data Used}

A range of data sources and GIS software were utilised for this study. Data collected from this study were existing PNG Geodata in digital vector and raster format and mostly field surveys. Data pertaining to PNG Geodata sets (PNGRIS, 2009) were Lithology, Soil, Landform, Road, Rainfall, Rivers drainage and SRTM DEM data for PNG at $30 \mathrm{~m}$ spatial resolution. GPS data were waypoints and track surveys for existing roads collected from field visits and Karimui conservation office. Most important part of the information from this study was expert's opinions on suitability factors and judgments on each parameter through personal interviews to draw up weightage. Published literatures from similar studies were accessed through internet to identify study techniques and possible factors to integrate in this analysis. Suitability analysis through MCE approach, ArcGIS software package was used while MapInfo and Google earth online softwares were used for data conversion and verifications.

\subsection{Research Methodology of this Study}

GIS and mathematical based methodology has been applied to identify suitable sites for road connectivity in mountainous and difficult terrain region. For the purpose of analysis, eight suitability factors were selected based on literature reviewed, personal observation, interviews and judgements from field experts. The factors were classified into two principal classes which are geophysical factors and geotechnical factors. Geophysical factors like slope, drainage, rainfall, altitude and road; and geotechnical factor like lithology, soil texture and landform were considered for this research.

The methodology involved; selection of factors, generation of data thematic layers in the GIS, data conversion in GIS, numerical rating assignment to factors, data integration in GIS, display and reporting suitability results (Figure 2). Data on soil type, lithology, landform, drainage density, rainfall and road maps from PNG Geodata sets were generated in ArcGIS 10, while terrain and slope map layers were prepared from SRTM DEM data for PNG at 30m spatial resolution by using ArcGIS 10 extraction and slope analysis tools. Thematic layer of factor maps were reclassified and integrated by employing single evaluation index method throughout the step. All the thematic layers were georeferenced and reprojected to a common standard WGS 1984 UTM rectangular coordinate system to perform spatial analysis in ArcGIS and ERDAS Image Softwares. From there, all map layers in vector format were rasterized to produce integrated thematic map layers. Right through the process of assigning weightage of each parameter the personal interviews with technical expertise articulated from opinions about the significance of one single pair wise comparison at a time are reflected as useful guide. By integrating multi-class thematic layers of geophysical and geotechnical factors through weighted overlay index techniques suitability sites were found and classified as less suitable, marginally less suitable, moderately suitable, suitable, and highly suitable. 


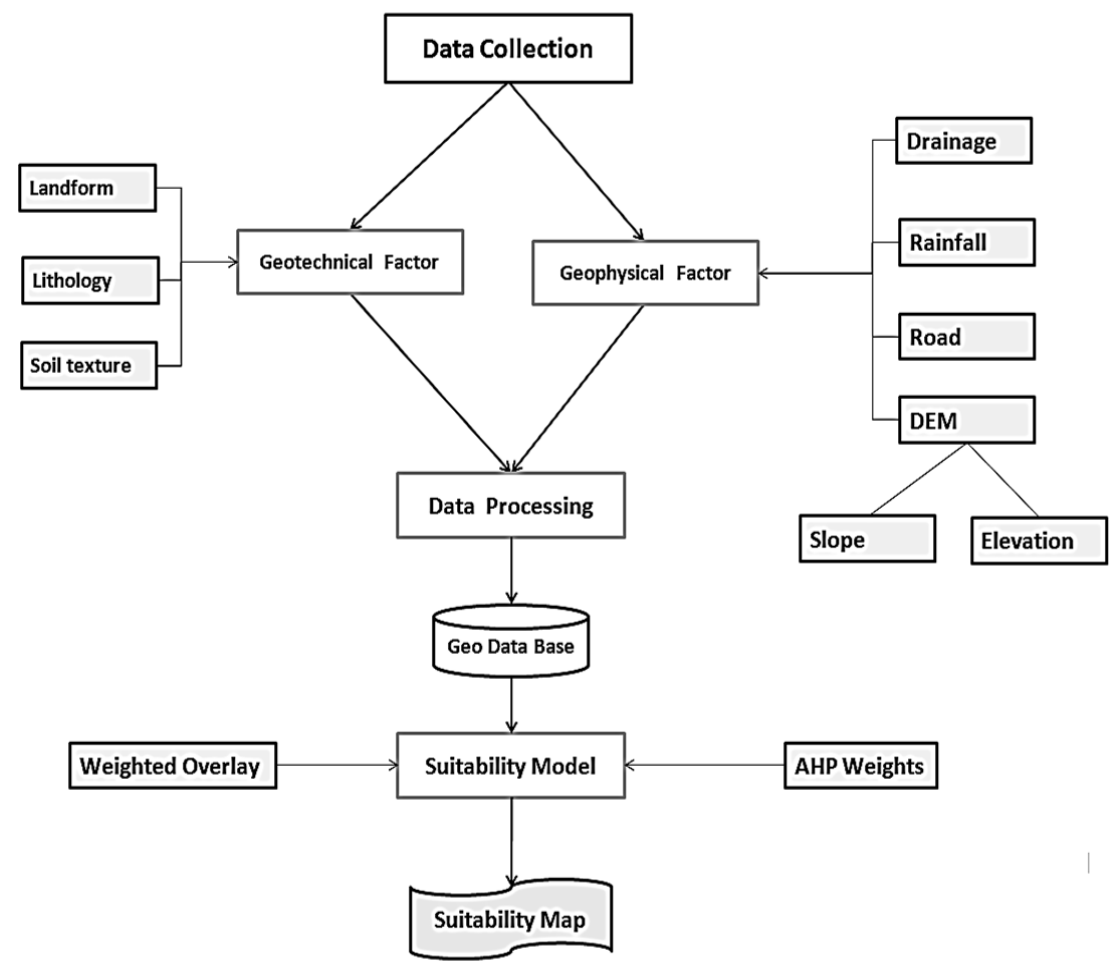

Figure 2: Methodology design layout for the study

Table 1: Suitability parameter classes and level of suitability

\begin{tabular}{|c|c|c|c|c|c|c|}
\hline \multicolumn{7}{|c|}{ Suitability Level } \\
\hline $\begin{array}{l}\text { Suitability } \\
\text { Indicator }\end{array}$ & Unit & S5 & S4 & S3 & $\mathbf{S 2}$ & S1 \\
\hline Lithology & Class & $\begin{array}{l}\text { Limestone/Mixed } \\
\text { metamorphic/Acid } \\
\text { to intermediate } \\
\text { Igneous }\end{array}$ & $\begin{array}{l}\text { Fine } \\
\text { sedimentary/ } \\
\text { Pleistocene } \\
\text { sediments }\end{array}$ & Pyroclastics & $\begin{array}{l}\text { Mixed or } \\
\text { undifferentiated } \\
\text { Sedimentary }\end{array}$ & $\begin{array}{l}\text { Mixed } \\
\text { Sedimentary \& } \\
\text { Volcanic/ basic } \\
\text { to intermediate } \\
\text { volcanic } \\
\end{array}$ \\
\hline Land Form & Class & $\begin{array}{l}\text { Homoclinal ridges \& } \\
\text { cuestas, inclined } \\
\text { asymmetrical } \\
\text { structurally } \\
\text { controlled ridges }\end{array}$ & $\begin{array}{l}\text { Little dissected } \\
\text { volcanic } \\
\text { footslopes\& } \\
\text { Volcano- } \\
\text { alluvial fans }\end{array}$ & $\begin{array}{l}\text { Volcanic } \\
\text { cones and } \\
\text { domes }\end{array}$ & $\begin{array}{l}\text { Strike ridge \& } \\
\text { hogback ridge } \\
\text { steep, sharp crested } \\
\text { structurally } \\
\text { controlled }\end{array}$ & $\begin{array}{l}\text { Mountains \& } \\
\text { Hills with weak } \\
\text { or no } \\
\text { structurally } \\
\text { control }\end{array}$ \\
\hline Soil Texture & Class & Sandy clay /Sand & Clay loam/Clay & Sandy loam & Silty (Clay/Loam) & $\begin{array}{l}\text { Sandy clay } \\
\text { loam }\end{array}$ \\
\hline Road & Kilometre & $0-10$ & $10-20$ & $20-30$ & $30-40$ & $40-50$ \\
\hline Rainfall & Millimetre & $2000-2500$ & $2500-3000$ & $3000-3500$ & $3500-5000$ & $5000-7000$ \\
\hline Slope & Degree & $<5$ & $5-10$ & $10-20$ & $20-30$ & $>30$ \\
\hline Drainage & Meter & $0.4-0.7$ & $0.7-1$ & $1-1.3$ & $<0.4$ & $>1.3$ \\
\hline Altitude & Meter & $1076-1406$ & $1406-1816$ & $764-1076$ & $1816-2988$ & $164-764$ \\
\hline
\end{tabular}

\subsubsection{Data evaluation approach}

In single evaluation index method, all thematic layers were reclassified into a common five point scale factor based on the intensity of geophysical and geotechnical influence on a site suitable for road as shown in Table 1. The Suitability levels were classified as highly suitable (S5), Suitable (S4) moderately suitable (S3), and marginally less suitable (S2) and less suitable (S1). AHP process was used to draw out relative importance of weights for every specific sort of influential factor articulating the comparative values of a set of attributes in the integrated analysis (Lukoko and Mundia, 2016).

\subsubsection{AHP suitability weightage}

AHP method is a decision support tool that can be used to develop relative importance weights (RIWs) to solve complex decision problems. The integration of multi-class thematic maps through simple 
weighted overly operations like this has no standard scale (Bhunia et al., 2012). Hence, criteria for the analysis are to be set up and each parameter should be assigned with weightage based on their suitability importance (Saraf and Choudhury, 1998 and Nag, 2005). Consequently, a pair wise comparison matrix was created by bring into play the Satty's analytical hierarchy process (Satty, 2008) to compute normalized weights for individual themes and their features. The steps through this study involve a multi-level hierarchical structure of objectives, integrated criteria, sub criteria, and alternative classes (Figure 3). That consist of objectives at the first, two principal factors at the second, eight subsidiary factors at the third and suitability alternatives are at the last levels respectively.

\subsubsection{Weightage index calculation based on}

\section{suitability assessment}

Integrating the thematic layers, suitable weights were assigned to common five point scale factor based on their suitability importance. The weights were given on a scale 1 to 9 based on Satty's (Satty,
2000) Analytic Hierarchy Process (Rao et al., 1991) for scaling the weights of parameters by building a pair wise comparison matrix. Ranking the weights of different influential features of each theme was assigned on a scale 1 to 5 according to their suitability intensity. Higher weightage i.e., 5 (five) is given to higher suitability indicator (S5) and lower weightage i.e., 1 (one) is for lesser suitability indicator (S1). In the course of weighted overly index technique, the classes of thematic maps generated in each input map layers are assigned by different scores, separate from the weights of each map layers. The average score of this process is then defined by employing the formula (Borham Carter, 1994) as shown in equation 1.

$$
S=\Sigma S i j W i / \Sigma W i
$$

Equation 1

Where, $\mathrm{S}$ is the weight score of an area object (polygon, pixel), Wi is the weight for the ith input map and Sij is the rating score of the jth class of the ith map.

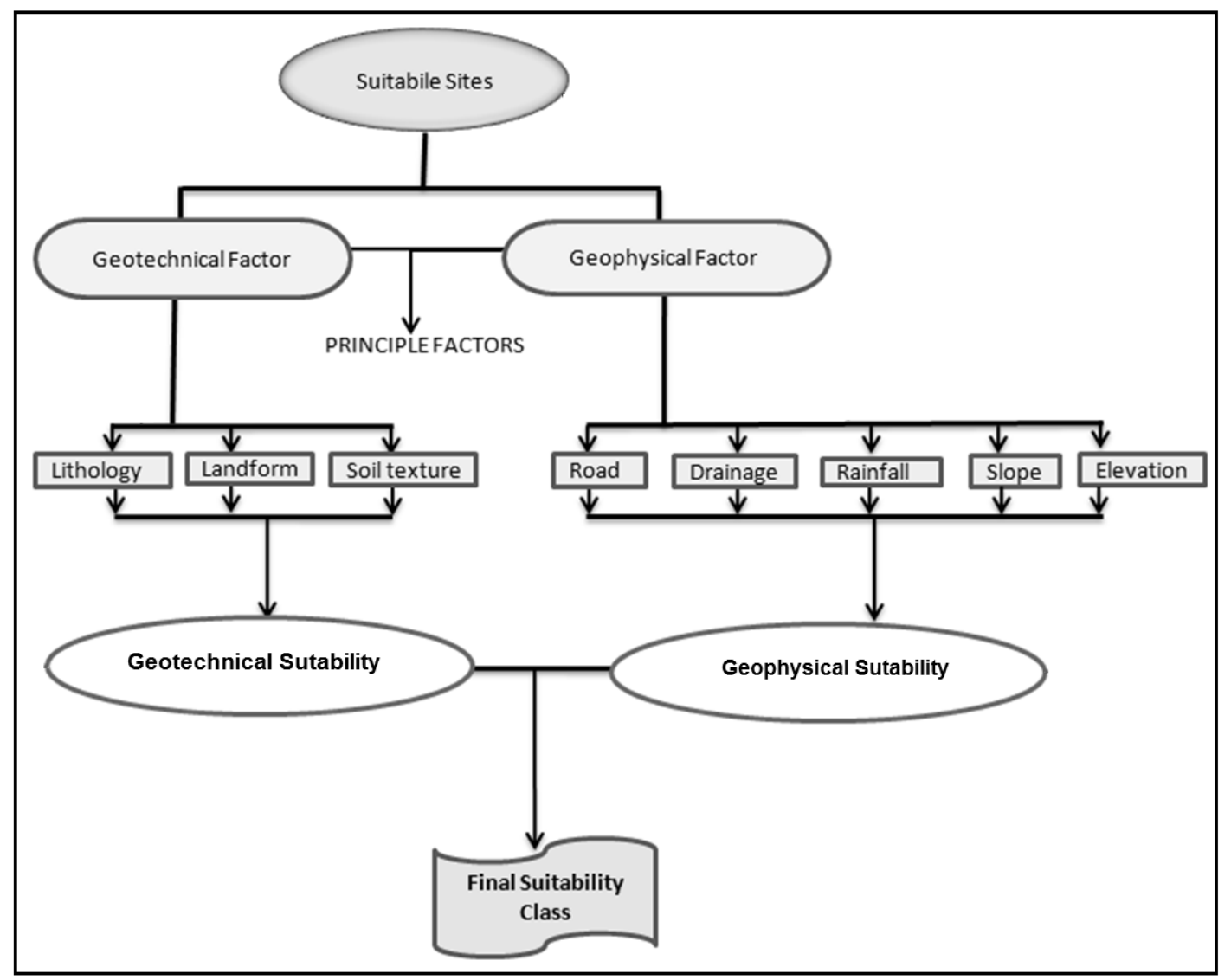

Figure 3: AHP suitability model diagram 


\subsubsection{Weight overlay model}

The overlay toolset contains tools to overlay multiple coverage to combine, erase, modify or update spatial feature into a new coverage. Spatial analysis of weighted overlay usually involves more than one thematic layers working through a series of steps to reach a final integrated result. This data integration model involves three stages of Weighted overlay operations as shown in Figure 4. The suitability evaluation method for integrating thematic layers was based on five point factors and that demonstrates the comparatively significance weights of each parameters and classes fit in to each parameter. The thematic layers of Geophysical factors were integrated after design weight in percentage like, $30 \%$ weight for slope, $20 \%$ for elevation, $20 \%$ for drainage density, $15 \%$ for rainfall and $10 \%$ for road database to produce the composite map layer of geophysical suitability classes (Table 2). Weight of 38\% for Lithology, $33 \%$ for landform and $29 \%$ for soil database were assigned and integrated to produce second composite map of geotechnical suitability classes (Table 2). The final suitability map was produced by combining both the two weighted composite map layers.

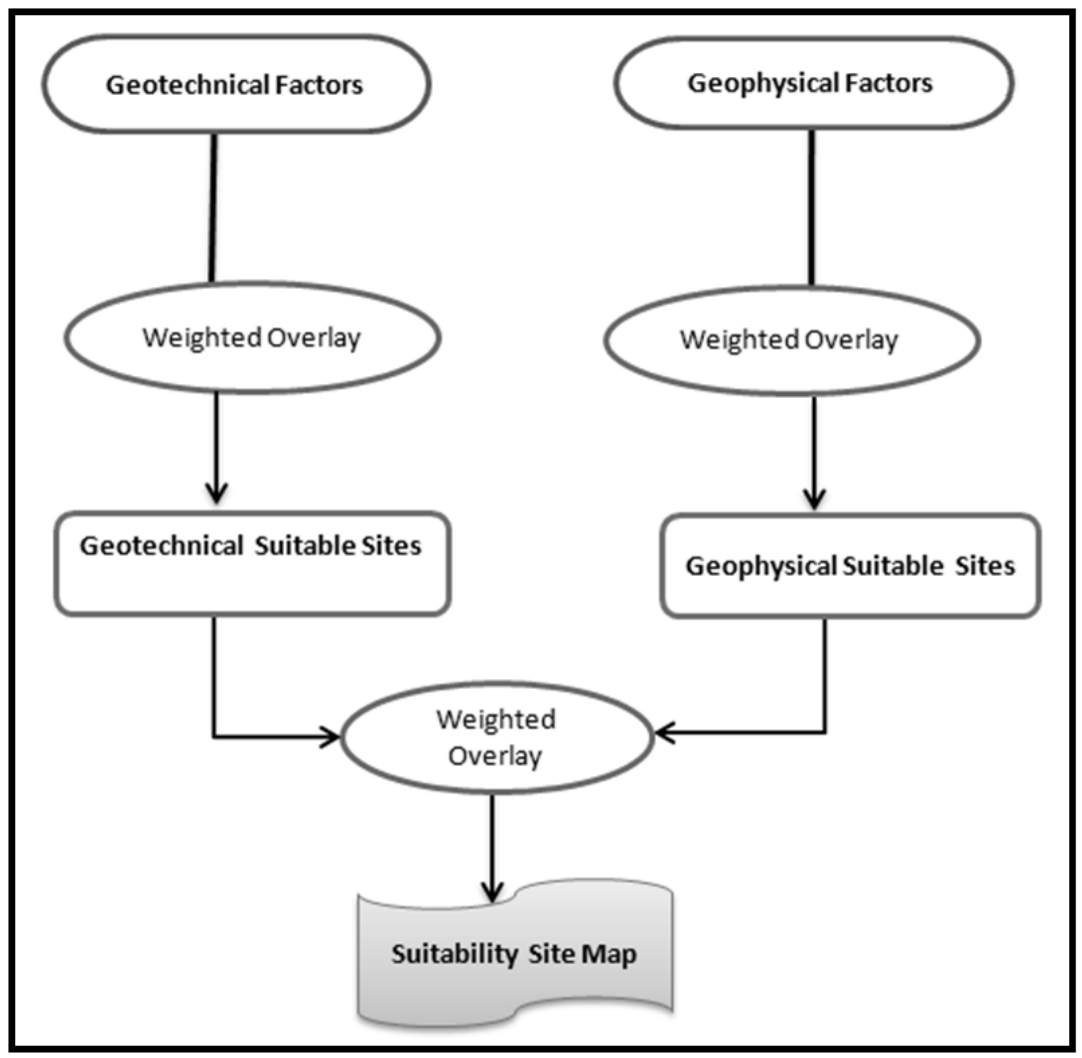

Figure 4: Schematic suitability model diagram

Table 2: Weightage of the suitability factors

\begin{tabular}{|l|l|c|}
\hline Principal Factors & Suitability Indicator & Weightage (\%) \\
\hline \multirow{3}{*}{ Geotechnical } & Lithology & 38 \\
\cline { 2 - 3 } & Landform & 33 \\
\cline { 2 - 3 } & Soil Texture & 29 \\
\hline \multirow{2}{*}{ Geophysical } & Slope & 30 \\
\cline { 2 - 3 } & Elevation & 25 \\
\cline { 2 - 3 } & Drainage Density & 20 \\
\cline { 2 - 3 } & Rainfall & 15 \\
\cline { 2 - 3 } & & 10 \\
\cline { 2 - 3 } & Road & \multicolumn{2}{|c|}{} \\
\hline
\end{tabular}




\section{Results}

The Reclassification maps of respective thematic layers using common five point scale are shown in various maps from Figures 5 to 6.The geophysical and geotechnical suitability maps are presented in
Figure 7. Final integrated suitability map and its spatial overlay map are shown in Figure 8 with the summary of suitability alternatives is shown in Table 3.

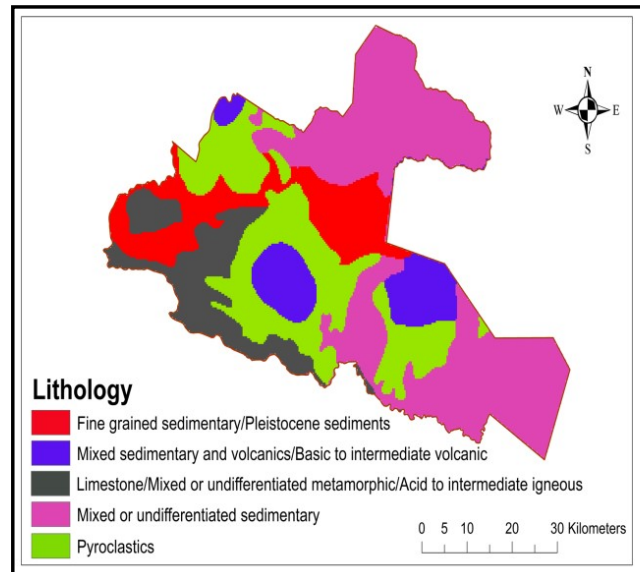

A

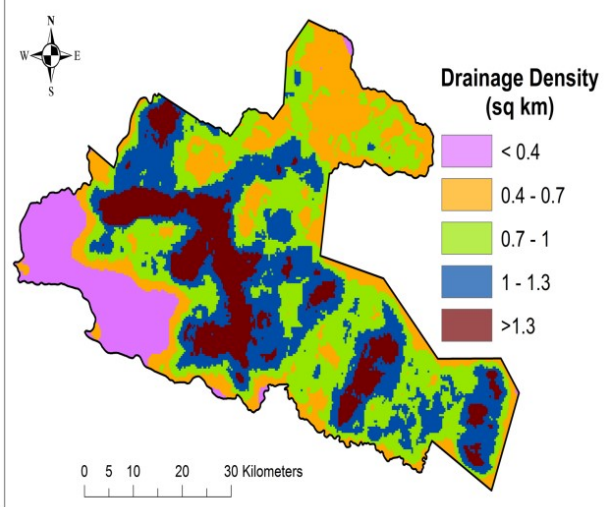

C

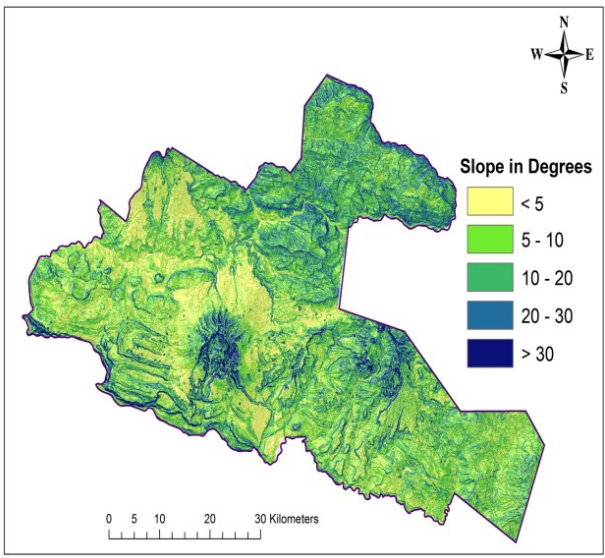

$\mathbf{E}$

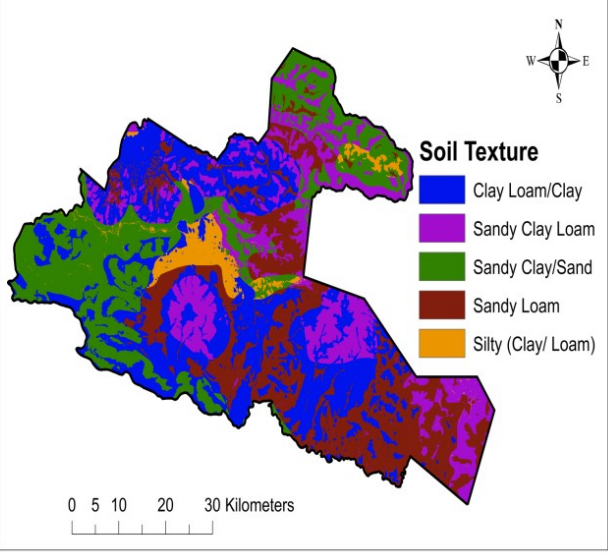

B

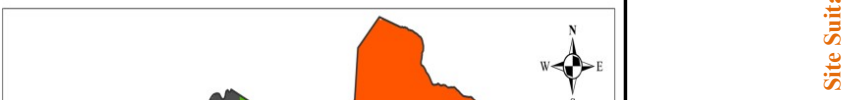

Landform

Mountains and hills with weak or no structural control

Homoclinal ridges and cuestas: inclined asymmetrical structurally controlled ridges Strike ridges and hogback ridges: steep, sharp crested structurally controlled ridges

Little dissected volcanic footslopes and volcano-alluvial fans

Volcanic cones and domes \begin{tabular}{ccccc}
0 & 5 & 10 & 20 & 30 Kilometers \\
\hline & 1 & 1 & + & +
\end{tabular}

D

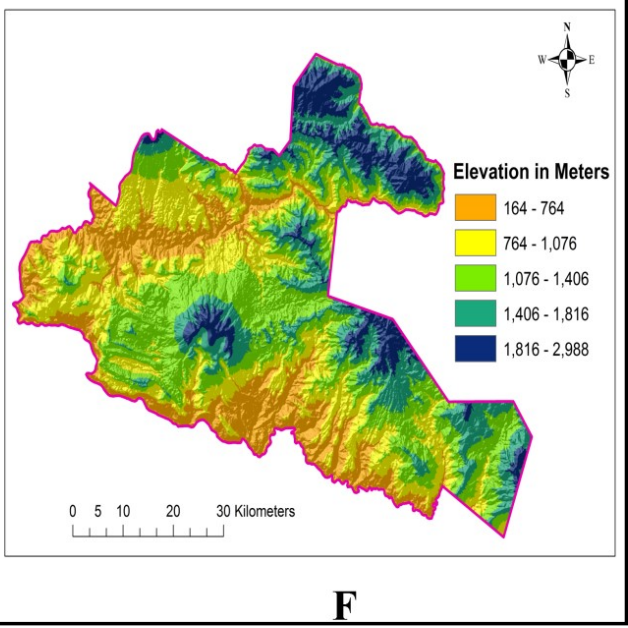

Figure 5: Reclassified Thematic Maps: A .Lithology; B. Soil texture; C. Drainage Density; D. Landform; E. Slope Angle; F. Elevation 


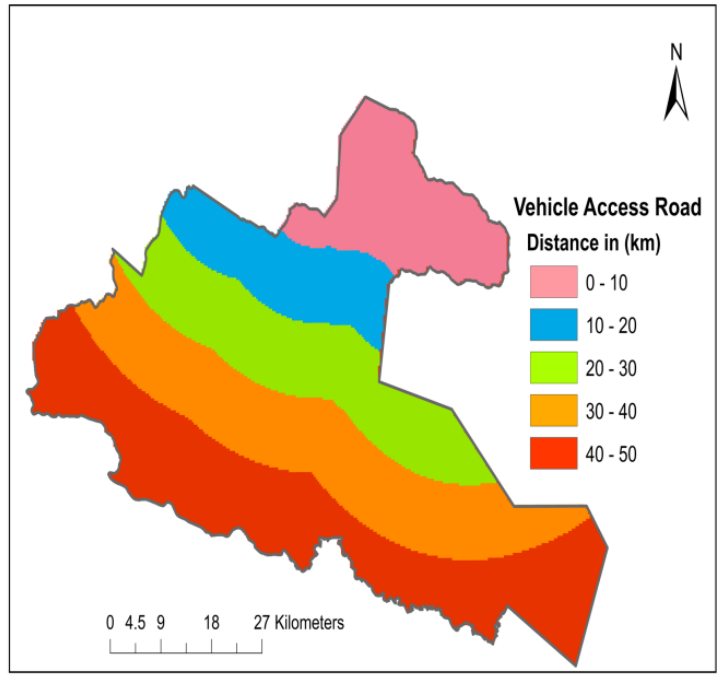

A

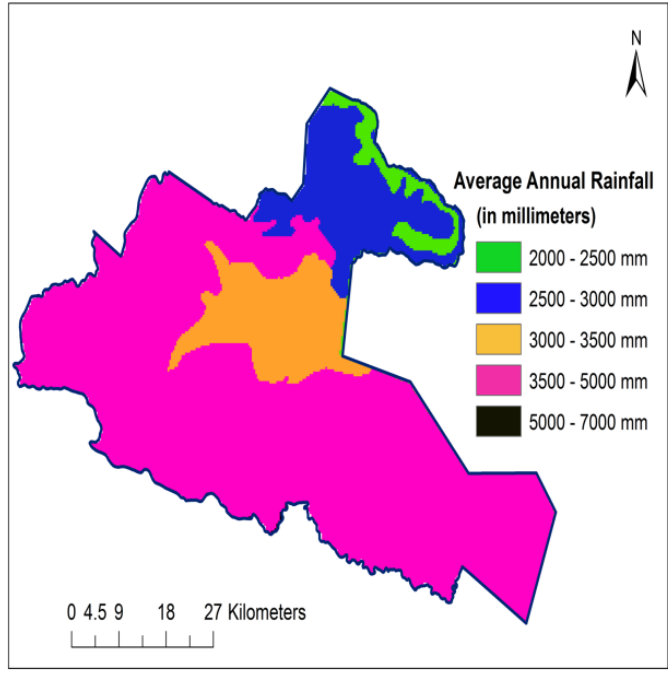

B

Figure 6: Reclassified thematic maps (A) Road accessibility and (B) Annual totalrainfall

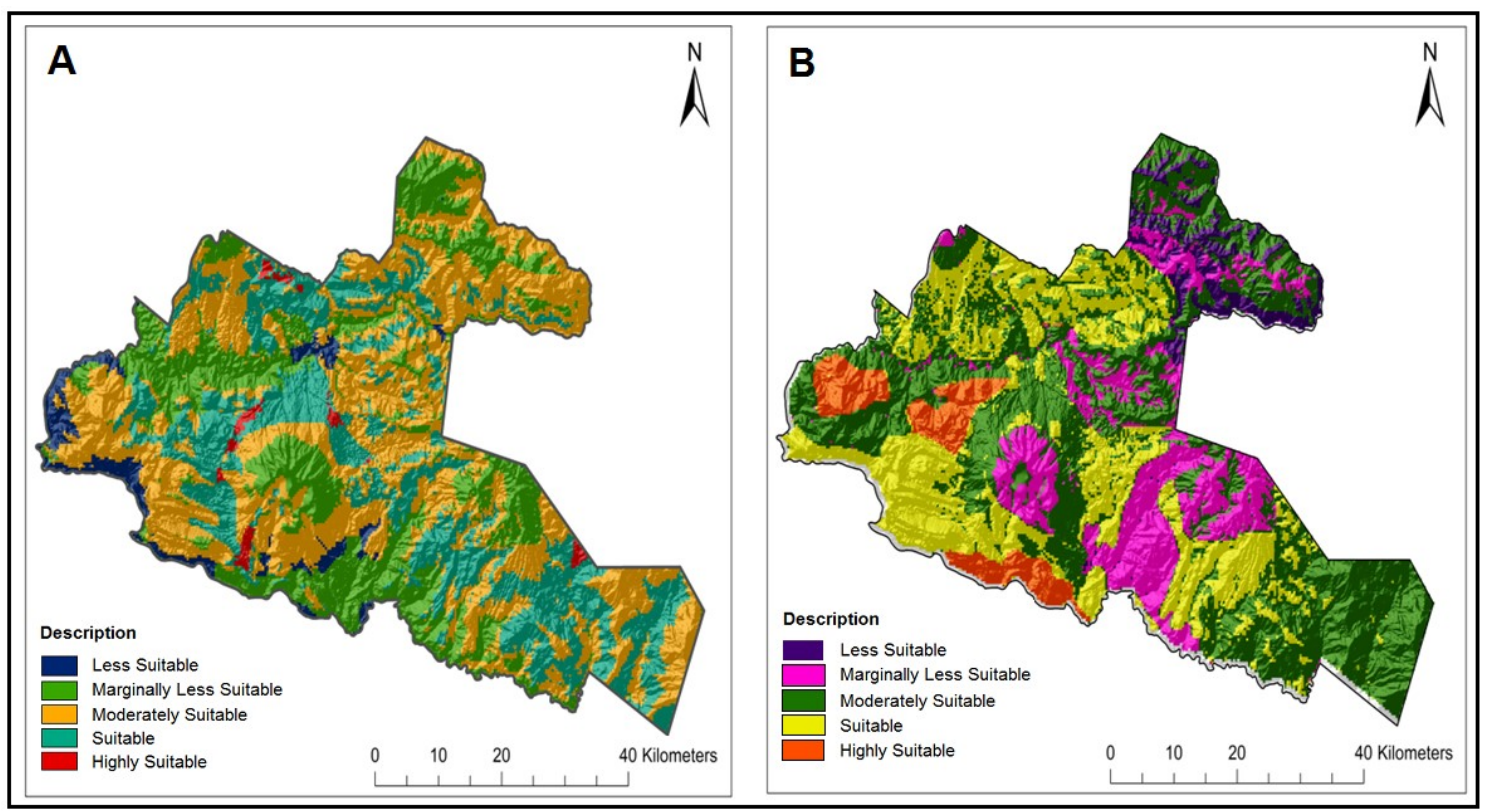

Figure 7: (A) Geophysical suitability and (B) geotechnical suitability map of the study area

The geological factors on the alignment and stability of roads such as Lithology amongst others are very important factors considered in planning and design process of any road construction. In Figure 5a shows the less suitable sites indicated with blue colour, marginally less suitable sites in pink colour, moderately suitable in green colour, Suitable site in red colour and highly suitable in black colour. It shows that marginally less suitable sites are predominantly cover large area spreading across south-east and large area in the northern region.
The soil type influences appropriate engineering designs to construct safe and sustainable road systems. In Figure 5b shows the less suitable site in pink colour and marginally less suitable in yellow colour, moderately suitable site in dark red colour, Suitable sites in blue colour and highly suitable soil texture in green colour. However, moderately suitable site covers wider area stretching across north to east, central and cover large area across the south east region. River/drainage systems have very serious consequences, both for integrity of the road pavement and stability of the hilly terrain. 
Table 3: Integrated suitability options

\begin{tabular}{|c|c|c|c|}
\hline \multicolumn{4}{|c|}{ Weighted Overlay Suitability Level } \\
\hline $\begin{array}{c}\text { Suitability } \\
\text { Alternatives }\end{array}$ & Class & Area (sqkm) & \% Cover \\
\hline \multirow{5}{*}{$\begin{array}{c}\text { Geophysical } \\
\text { Suitability Sites }\end{array}$} & Less Suitable & 178.8 & 4.57 \\
\hline & Marginally Less Suitable & 1067.67 & 27.26 \\
\hline & Moderately Suitable & 1595.05 & 40.73 \\
\hline & Suitable & 987.85 & 25.22 \\
\hline & Highly Suitable & 87.09 & 2.22 \\
\hline \multirow{5}{*}{$\begin{array}{c}\text { Geotechnical } \\
\text { Suitability Sites }\end{array}$} & Less Suitable & 209.6 & 5.33 \\
\hline & Marginally Less Suitable & 1029.98 & 26.21 \\
\hline & Moderately Suitable & 1771.8 & 45.1 \\
\hline & Suitable & 657.2 & 16.72 \\
\hline & High Suitable & 261.87 & 6.66 \\
\hline \multirow[t]{5}{*}{ Final Suitability Sites } & Less Suitable & 76.61 & 2.01 \\
\hline & Marginally Less Suitable & 674.66 & 17.73 \\
\hline & Moderately Suitable & 1865.74 & 49.03 \\
\hline & Suitable & 1106.61 & 29.08 \\
\hline & Highly Suitable & 81.93 & 2.15 \\
\hline
\end{tabular}

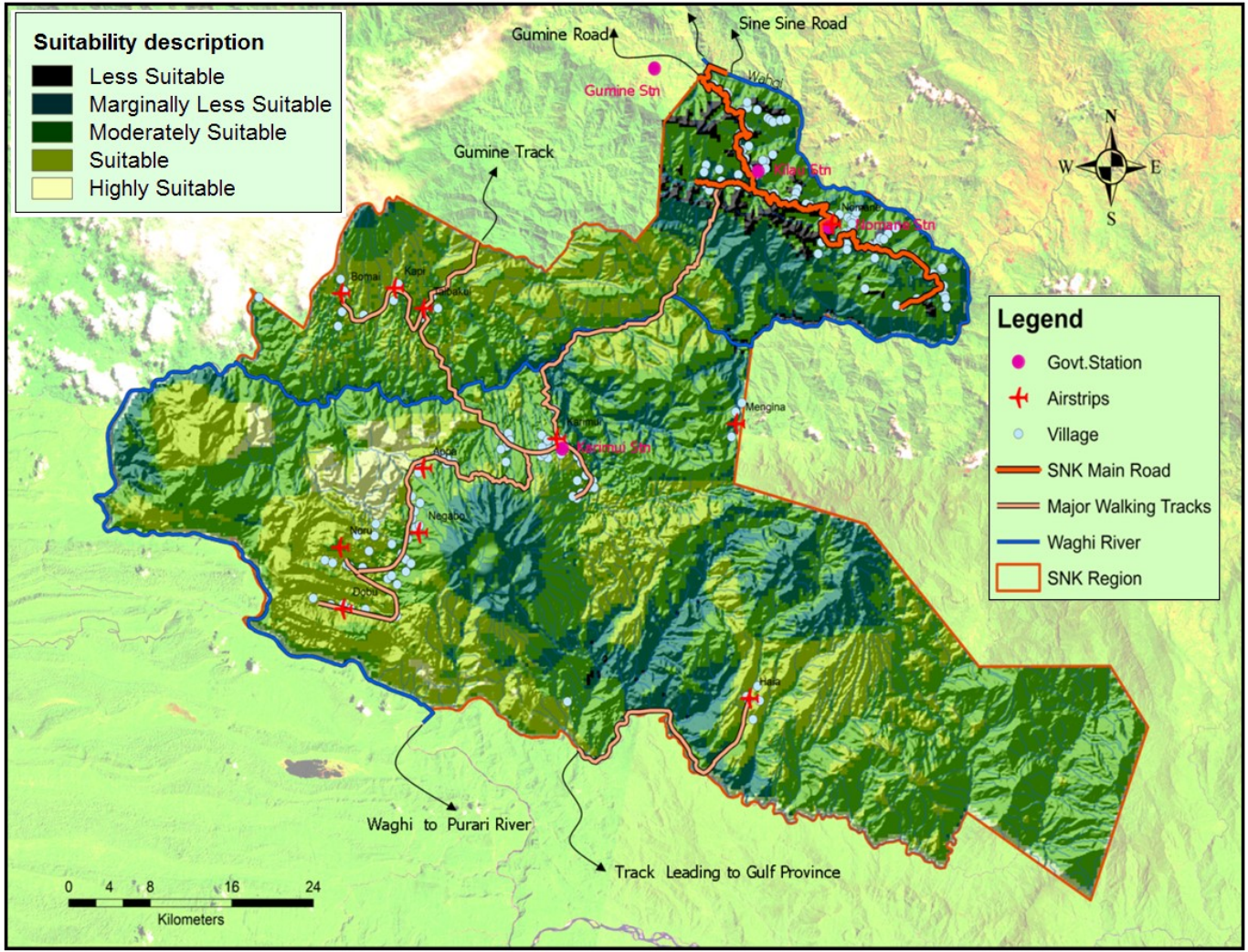

Figure 8: Final suitability mapwith overlayed infrastructures 
It should be taken extraordinary note in this study that low density and high density areas is not fitting for any contraction purposes as expressed by field experts and revealed by personal observation as it is predominantly found at the peaks of mountain ranges, rocky hills, base of V-shape valleys and steep clips along the river banks and streams line at the lower altitudes. In Figure 5c shows the less suitable in dark red colour and measured $>1.3 \mathrm{sq}$ $\mathrm{km}$, marginally less suitable site in pink colour and measured $<0.4 \mathrm{sq} \mathrm{km}$, moderately suitable in blue colour and measured 1-1.3 sq km, Suitable site in green colour and measured between 0.7-1 sq km, while highly suitable sites in dark yellow colour and measured between 0.4-0.7 sq $\mathrm{km}$. It shows that highly suitable, suitable and moderately suitable followed by less suitable cover most of the study region.

Landform is important to designers because they often place substantial limitations on the location, intensity, and character of any physical infrastructural development. In Figure 5d shows the less suitable as exposed in red colour, marginally less suitable is shown in yellow colour, moderately suitable is presented with black colour, suitable site is shown in green colour and highly suitable land formation is shown in blue colour. It has exposed that less suitable land formation covers most part of the region, as it covers northern region spreading across south-east and south- west fringes.

Slope plays important role as it affects land stability. As the steepness of the slope increases, possibility of slope failure also increases, (Pareta et al., 2012). If the road alignment positions itself on a suitable geographical surface then, it is considered most stable as these sites are well-suited to low-cost methods of slope protection and stabilization work and subsequently less likely to cause environmental mischief. In Figure 5e shows that highly suitable site for slope factor is in autunite yellow colour and measured $<5$ degrees, suitable site is in light green colour and measured 5-10 degrees, moderately suitable site is in malachite green colour and measured between 10-20 degrees, marginally less suitable is in light blue colour and measured between 20-30 degrees and unsuitable sites is in dark blue colour and measured $>30$ degrees. In the mountainous region, slope angle ranging from 20 30 degrees creates excessive ecological and technical problems at the landscape level and expensive to build roads. Slope angle measured $>30$ degrees is prohibitively expensive and extremely damaging to terrain as it is very steep and technically not fitting for road construction. However for social or economical reasons deem necessary, it must be planned with extreme care as it is technically and economically impractical for any construction. Unfortunately this region is unsuitable for construction as more than half of the region is measured over 30 degrees and predominantly covers northern, part of central, southern, western and part of eastern fringe.

Altitude influences road projects as it creates so much geotechnical challenges. It should be noted that, lower altitude is obviously difficult for construction as for most part of it covers fast flowing river banks with extensive rock formations and steep clips. It also covers V-shape valleys often have rivers and streams at the base which poses flooding and landslide problems. Higher altitude is also not-fitting for road as it covers steep hilly edges, sloppy ridges and sharp rocky mountain tops. In Figure 5f shows that less suitable is measured from $164-764 \mathrm{~m}$ with dark yellow colour, marginally less suitable is measured between $1816-2988 \mathrm{~m}$ and shown in blue colour, moderately suitable site falls between $764 \mathrm{~m}-1076 \mathrm{~m}$ as indicated with yellow colour, suitable site falls between $1406 \mathrm{~m}-1816 \mathrm{~m}$ as shown in dark green colour and highly suitable site range from $1076 \mathrm{~m}-1406 \mathrm{~m}$ as provided in light green colour. It has revealed that northern region and part of southern region and southern -west fringes are unsuitable for construction purposes.

Distance from existing road network to target region is important as shortest distance save time and cost. Figure 6a shows that less suitable falls from $40 \mathrm{~km}$ to $50 \mathrm{~km}$ in red colour, marginally less suitable from $30 \mathrm{~km}$ to $40 \mathrm{~km}$ as shown in yellow colour. Moderately suitable from $20 \mathrm{~km}$ to $30 \mathrm{~km}$ in green colour and suitable stretch from $10 \mathrm{~km}$ to $20 \mathrm{~km}$ in light blue colour while highly suitable measured within $0-10 \mathrm{~km}$, in purple colour mainly found within north region. It shows that existing roads are within the northern region and as such highly suitability sites are stretching from north to southern end. Rainfall influences surface and underground stability and integrity of road pavement and stability of adjacent terrain. In Figure 6b shows annual rainfall ranging from lowest to highest in millimetres. Highly suitable site falls between $2000 \mathrm{~mm}-2500 \mathrm{~mm}$ in green colour and suitable site in blue colour ranging from $2500 \mathrm{~mm}$ $3000 \mathrm{~mm}$, cover the entire northern region, while moderately suitable sites in yellow colour, from $3000 \mathrm{~mm}-3500 \mathrm{~mm}$ covers part of central region. Marginally less suitable in pink colour falls between $3500 \mathrm{~mm}-5000 \mathrm{~mm}$ covers the retire southern region and less suitable in black colour from $5000 \mathrm{~mm}$ $7000 \mathrm{~mm}$ with little presence in the northern fringes. 


\section{Discussion}

Weight assigned to layers of suitability indicators were based on the strength of its influence on the surface and sub-surface layers of physical terrain suitable for road construction. The weightings of parameters is based on Satty's Analytic Hierarchy Process (Rao et al., 1991) of scale 1 to 9 as it is widely accepted method for scaling the weights of parameters by constructing a pair wise comparison matrix where entries point out the strength with which one element dominates over another vis-à-vis the relative criterion. The alternative Geophysical suitability map in Figure 7a shows less suitable class in blue colour, marginally less suitable class in green colour, moderately suitable class in yellow colour, suitable class in malachite green colour and highly suitable class in red colour. Moderately suitable covers more than half of the region while marginally less suitable covers most part of the remaining region. Suitable and highly suitable cover few parts of northern, central, north-west and southwest respectively. Less suitable covers few areas in southern region and few spot on the east.

The alternative Geotechnical suitability map in Figure $7 \mathrm{~b}$ indicates less suitable class in ultramarine colour, marginally less suitable class in peony pink colour, moderately suitable class in dark green colour, suitable class in yellow colour and highly suitable class in fire red colour. Moderately suitable covers most of the region while suitable and marginally less suitable cover big fraction of the remaining. Highly suitable and suitable covers some part of northern, central and south-west region while less suitable covers few areas in the northern region.

The final suitability map (Figure 8) is the composite overlay product of geophysical suitability map and geotechnical suitability map. Final integrated map shows that moderately suitable to marginally less suitable and less suitable are only appeared in northern part of the region. Few parts of southern region covers marginally suitable while highly suitable to suitable, combined with moderately suitable zones are found in central spreading across east to western end and southern part of the region. Both integrated geophysical and geotechnical suitability maps shows that northern and few areas of Southern region are not fitting for construction purposes. Practically northern part of the region having most difficult geography of the landscape that constitutes mountain ranges and difficult terrain which makes it a challenge for the authorities to extend road to Karimui region.
Government of PNG to extend access to basic infrastructural services including road to the dispersed population living in rural areas. Plans and targets have been in place for rural road connectivity but their objectives are not met and/or delivered up to their expectation mainly due to technical challenges. This paper has put out a quantitative approach for identifying most appropriate sites for forest terrain and mountainous road network using GIS and MCE approach. The use of AHP permitted the derivation of relative weights of each influential factor for suitability assessment. However, GIS and MCE method developed in this research is appropriate for initial planning process. Moreover the results from this model depend upon data accuracy. Site specific technical and environmental factors may integrate into the model for more comprehensive result to incorporate construction costs and site specific route evaluation and selection.

This report provides the public and administrative governing agencies with a clear understanding of the road construction activities and budgeting requirements for the area, over the time period of planning process. Site Suitability alternatives provide both geotechnical and geophysical information in an integrated approach for planners and decision makers to take costeffective and environmental friendly planning approach for road in mountainous and difficult terrain region of SNK district. The site suitability map with overlay of existing vehicle access road and tracks in figure 8 shows the level of alternatively suitable pathways for connecting Karimui and possible sites for road connectivity within the region. The two walking tracks connect to vehicle access road are their only best possible and easy access pathway based on the local knowledge but often find it tough to walk due to difficult terrain and the unbearable walking distance. This type of analysis and research can be tools to help planners, engineers, governments and those in the community to plan in identification of lands in different condition like geophysical and geotechnical conditions for site selection and transportation requirements. Based local knowledge with site suitability level of integrated geotechnical and geophysical factors can provided the best alternatives for planners and decision makers to take cost - effective and environmentally friendly planning approach to connect Karimui region by road.

\section{Conclusion}

Difficult geography, lack of reliable technical data and planning tool makes it a challenge for the 


\section{Reference}

Abdi, E., Majnounian, B., Darvishsefat, A., Mashayekhi, Z. and Sessions, J., 2009, A GISMCE Based Model for Forest Road Planning. Journal of Forest Science, Vol. 55, 171-176.

Adedeji, O. A., Olafiaji, E. M., Omole, F. K., Olanibi, J. A. and Lukman, Y., 2014, An Assessment of the Impact of Road Transport on Rural Development: A Case Study of Obokun Local Government Area of Osun State, Nigeria. British Journal of Environmental Sciences, Vol. 2(1), 34-48.

Bhunia, G. S., Samanta, S. and Pal, B., 2012, Deciphering Prospective Ground Water Zones of Morobe Province, Papua New Guinea. International Journal of Engineering Research and Applications, Vol. 2 (3),752-766.

Bonham-Carter, G. F., 1994, Geographic Information Systems for Geoscientists: Modelling with GIS. Elseviers Science Ltd., 398.

Couter, E. D., Coakley J. and Sessions J., 2006, The Analytic Hierarchy Process: A Tutorial for use in Prioritizing Forest Road Investments to Minimize Environmental Effects. International Journal of Forest Engineering, Vol. 17, 51-70.

Davis, A., 2000, Transport and Sustainable Rural Livelihoods in Zambia; A Case Study; Egypt Social Fund for Development, Transport Research Laboratory. http://citeseerx.ist.psu.edu/viewdoc/download?d oi=10.1.1.436.5758\&rep=rep1\&type=pdf.

Dean, D. J., 1997, Finding Optimal Routes for Networks of Harvest Site Access Roads using GIS-based Techniques. Canadian Journal of Forest Resources, Vol. 27, 11-22.

Jun, C., 2000, Design of an Intelligent Geographic Information System for Multi-Criteria Site Analysis. URISA Journal, Vol. 12, 5-17.

Lukoko, P. and Mundia, C., 2016, GIS Based Site Suitability Analysis for Location of a Sugar Factory in Trans Mara District. International Journal of Sciences: Basic and Applied Research (IJSBAR), Vol. 25(3), 324-339.

Nag, S. K., 2005, Application of Lineament Density and Hydrogeomorphology to Delineate Groundwater Potential Zones of Baghmundi Block in Purulia district, West Bengal, Journal of Indian Society of Remote Sensing, Vol. 33(4), 513-521.

Pareta, K., Kumar J. and Pareta, U., 2012, Landslide Hazard Zonation Using Quantitative Methods in GIS, International Journal of Geospatial Engineering and Technology, Vol. 1(1), 1-9.
PNGRIS, 2009, Papua New Guinea Resource Information System. The Land-Use Section, Science and Technology Branch, Department of Agriculture and Livestock, 3rd ed.; University of Papua New Guinea: Boroko, Papua New Guinea.

Rao, M., Sastry, S. V. C., Yadar, P. D., Kharod, K., Pathan, S. K., Dhinwa, P. S., Majumdar, K. L. and Kumar, D. S., 1991, A Weighted Index Model for Urban Suitability Assessment-A GIS Approach Case Study for Bombay Metropolitan Regional Development Authority, Bombay. Project Report SAC/RSA/NRISURIS/TN03/February, Space Applications Centre and Bombay Metropolitan Region Development Authority.

Samanta, S., Pal, B. and Pal, D. K., 2011, Land Suitability Analysis for Rice Cultivation Based on Multi-Criteria Decision Approach through GIS. Int. J Sci. Emerging Tech, Vol. 2(1), 1219.

Saraf, A. K. and Choudhury, P. R., 1998, Integrated Remote Sensing and GIS for Groundwater Exploration and Identification of Artificial Recharge Sites. International Journal of Remote Sensing, Vol. 19(10), 1825-1841.

Satty, T. L., 1980, Analytic Hierarchy Process: Planning, Priority Setting, Resource Calculation, McGraw-Hill International Book Company, New York and London.

Satty T. L., 2000, Fundamentals of Decision Making and Priority Theory with AHP, Pittsburgh, RWS Publications.

Satty, T. L., 2008, Decision Making with the Analytic Hierarchy Process, Int. J. Services Sciences, Vol. 1(1), 83-98.

Shiba, M., 1995, Analytic Hierarchy Process (AHP) Based Multi Attribute Benefit Structure Analysis of Road Network Forest Road Investments to Minimize Environmental Effects. International Journal of Forest Engineering, Vol. 17, 51-70. 